\title{
Familial Focal Epilepsy with Variable Foci 1
}

National Cancer Institute

\section{Source}

National Cancer Institute. Familial Focal Epilepsy with Variable Foci 1. NCI Thesaurus.

Code C161005.

An autosomal dominant familial form of epilepsy caused by mutation(s) in the DEPDC5 gene, encoding GATOR complex protein DEPDC5. It is characterized by focal seizures usually arising from the frontal or temporal lobe. The onset of seizures may occur from infancy to adulthood. 